\title{
Embolic Sulcal Artery Stroke : Report of Two Cases
}

\section{Saini $M^{1}$}

1 Department of Neurology, Changi General Hospital, Singapore

\section{OBJECTIVE :}

To describe two rare cases of Embolic, Sulcal Artery Infarcts.

\section{BACKGROUND:}

Spinal cord infarction accounts for $<2 \%$ of all strokes.

Majority of spinal infarcts occur in the setting of aortic surgery or manipulation, involve the Anterior Spinal Artery territory, and present as an anterior cord syndrome.

Sulcal Arteries arise from the anterior spinal artery, and tend to alternate in their distribution to the left or right side of the spinal cord. Sulcal Artery infarcts are rare, and have previously been reported predominantly in relation to vertebral artery dissection.

Here, two cases of embolic Sulcal Artery infarcts, presenting as Brown-Séquard Syndrome, are described.

\section{RESULTS}

\section{CAse 1:}

A 64 year old gentleman, with history of hypertension, hyperlipidemia and ischemic heart disease was admitted for recurrent hemoptysis. Bronchial artery embolization ( BAE) was performed via femoral approach; bronchial arteries ( 1 right ; 2 left) and hypertrophic right 3rd intercostal artery were embolized with glue. Acute onset of right lower limb numbness, followed by progressive (over several hours) weakness and urinary retention, were noted immediately post-procedure.

Clinical examination was significant for findings of BrownSéquard syndrome (BSS), with a sensory level at T4-5 and power grade 0-2 in right lower limb. Magnetic resonance imaging of the spine ( 48 Hours) showed T2 hyperintensities in the thoracic spine, largest of which was at T3-4 level (right hemicord; Figure $1 a$ and $b$ ). Diagnosis of BSS secondary to embolic sulcal artery infarct, as a complication of BAE, was made. Patient was managed conservatively.

\section{Case 2:}

A 74 year old gentleman, with history of hypertension, hyperlipidemia, diabetes, and ischemic heart disease was admitted with sudden onset lower sternal pain, tingling in right chest and abdomen, followed by numbness and weakness of the right lower limb.

\section{REFERENCES:}

1. Sandson TA, Friedman JH. Spinal cord infarction. Report of 8 cases and review of the literature. Medicine (Baltimore) 1989;68:282-292.

2. Li Y, Jenny D, Bemporad JA, Liew CJ, Castaldo J. Sulcal artery syndrome after vertebral artery dissection. J Stroke Cerebrovasc Dis. 2010 Jul-Aug;19(4):333-5
Clinical examination was significant for BSS ( power grade 2 in right lower limb). MRI spine showed a short segment T2 hyperintensity at $\mathrm{T} 4-5$ region ( Figure $2 \mathrm{a}$ and $\mathrm{b}$ ).

CT Aortogram showed chronic dissection flap at the mid descending thoracic aorta, with complete thrombosis of the false lumen. Diagnosis of sulcal artery infarct, secondary to embolus [of aortic origin] was made. Patient was managed conservatively.

Clinical Course : Clinical improvement to independent ambulation was noted in both cases, over a follow-up period of 4-5 months.

\section{CONCLUSIONS}

Though rare, Brown-Séquard syndrome may occur as a consequence of spinal Sulcal Artery infarcts. Prognosis of sulcal artery infarcts may be better as compared to anterior spinal artery infarcts.
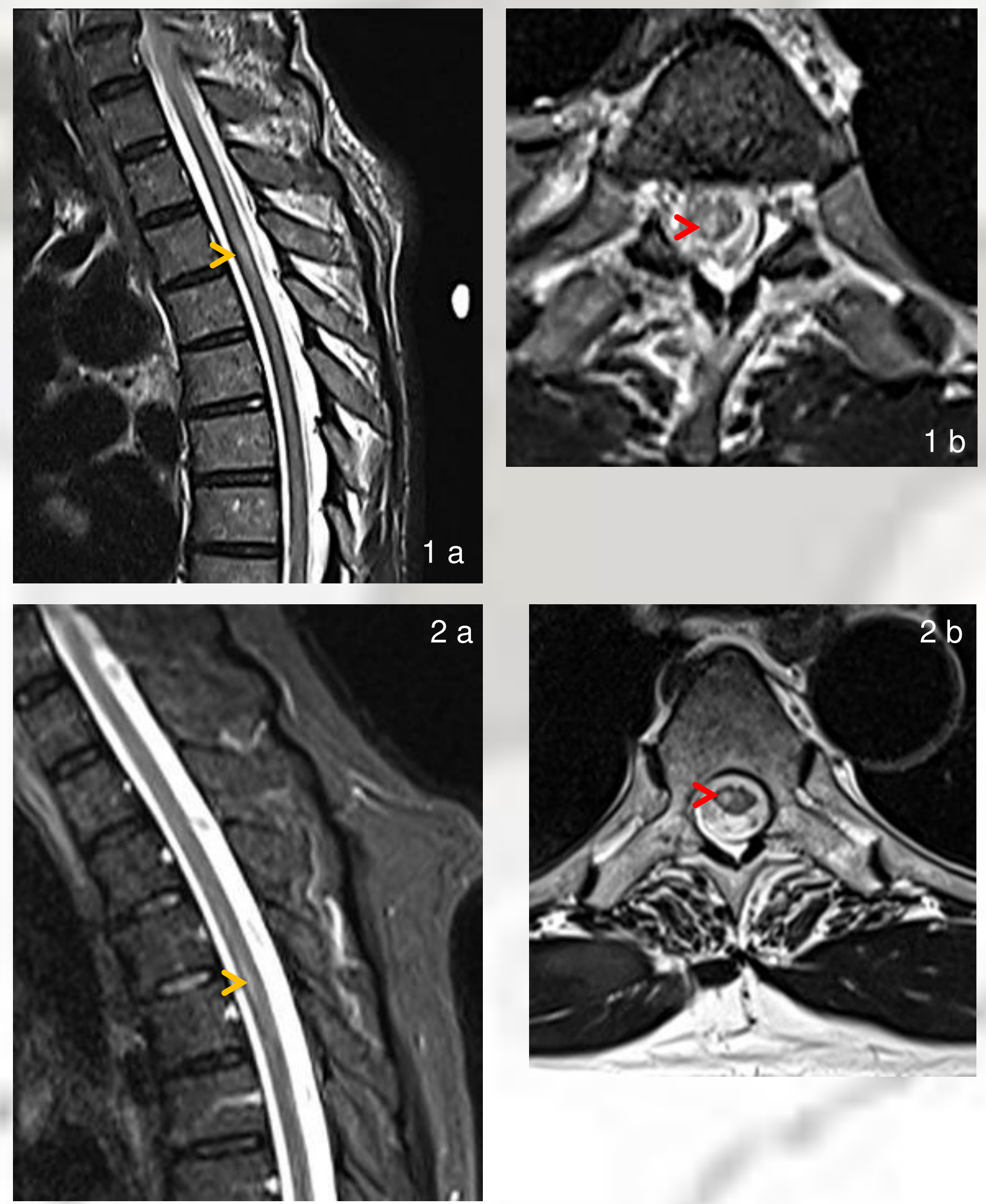

Figure : Focal, T2 weighted hyperintensities seen on saggital ( $1 a$, 2a; Orange arrowheads) and axial ( $1 b, 2 b$; red arrowheads) sections of the thoracic spinal cord. 